\title{
XXIV. On Mengite, a new species of mineral; on the characters of aeschenite; On sarcolite, as distinct from analcime and gmelinite; with other mineralogical notices
}

\author{
H.J. Brooke Esq. F.R.S. L.S. G.S.
}

To cite this article: H.J. Brooke Esq. F.R.S. L.S. G.S. (1831) XXIV. On Mengite, a new species of mineral; on the characters of aeschenite; On sarcolite, as distinct from analcime and gmelinite; with other mineralogical notices, Philosophical Magazine Series 2, 10:57, 187-191, DOI: 10.1080/14786443108675516

To link to this article: http://dx.doi.org/10.1080/14786443108675516

$$
\text { 曲 Published online: } 14 \text { Jul } 2009 .
$$

Submit your article to this journal ¿

\section{Џ Article views: 1}

Q View related articles ¿ 
expert in climbing, nor so tenacious of life under similar circumstances. I may remark, that in experiments instituted to decide how long spiders can live without food, the influence of season should not be disregarded. In winter, unless a high temperature be maintained by artificial means, the vital functions are performed with much less energy than they are in summer: of course the natural demand for sustenance, if it do not cease altogether, is greatly diminished in the former period, and the animals suffer little comparatively from abstinence.

Another spider of a diminutive size, frequently observed to take aërial excursions, is the Drassus ater of Latreille, which appears to be identical with the Aranea obtectrix of Bechstein.

Aëronautic spiders, properly so called, or those species which instinctively employ their lines to sail in the atmosphere, will probably be found almost exclusively among such as are active during the day and decidedly erratic. Numerous facts tend to corroborate this idea, the correctness or inaccuracy of which can only be determined by more extended observations.

XXIV. On Mengite, a new Species of Mineral; on the Characters of Aeschenite; on Sarcolite, as distinct from Analcime and Gmelinite; with other Mineralogical Notices. By H. J. Ввооке, Esq. F.R.S. L.S. \& G.S.

\section{Ilmenite.}

A MiNERAL under this name is said to have been deA scribed in 1821 in Kastner's Archir), \&c. No. 1. by Prof. Kupffer of Kasan. It was discovered by Mr. Mengé, near Lake Ilmen in Siberia, accompanied occasionally by a titanious iron-ore in modified rhomboids, of which a description and figure, but without measurements, were given by Mr. Levg in the Phil. Mag. and Annals, N.S. vol. i. p. 26.

Probably from having seen only the iron-ore, Prof. Rose of Berlin has stated that this was the ilmenite of Kupffer. The ilmenite is, however, a distinct substance, having for its primary form a right rhombic prism of $196^{\circ} 30^{\prime}$, the terminal edge being to the lateral edge very nearly as 17 to 11 . The colour is a more intense black than the rhomboids of titanious iron, and the surfaces of some of the crystals are perfect and brilliant. I have not observed any cleavage; the fracture is uneven to conchoidal with a vitreous lustre. Spec. grav. 5.4.5. Scratches glass slightly. The matrix is cleavelandite.

The crystals I have examined are generally small, length$2 \mathrm{~B} 2$ 
ened in the direction of the axis of the prism, and modified as in the accompanying figure.
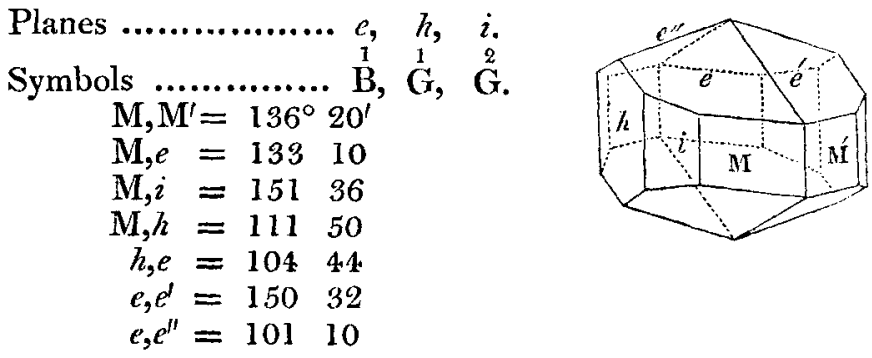

The spec. grav. of the titanious iron is $4 \cdot 74$. Hardness much less than oligiste iron. The measurements of Mr. Levy's figure are

$$
\begin{aligned}
& p, a 1 \ldots . .=122^{\circ} 6^{\prime} \\
& p, p \text {, below } 85 \quad 36 \quad 86^{\circ} 10^{\prime} \quad 85^{\circ} 59^{\prime}
\end{aligned}
$$

I give the axotomous iron on the authority of Mr. Haidinger's Mineralogy.

Mr. Levy's $e 3$ does not occur on the crystals I have seen; but I find the planes of an obtuse rhomboid, produced by tangent planes on the terminal primary edges, and calling these $b 1$, they give the following measurements:

$$
\begin{aligned}
& a 1, b 1=141^{\circ} 26^{\prime} \\
& b 1, b^{\prime} 1=11438
\end{aligned}
$$

\section{Aeschenite.}

This mineral, which was also discovered and brought from Siberia by Mr. Mengé, and at first considered by him as gadolinite, has been analysed by Hartwell, and named by Berzelius; but as far as I can discover, not otherwise described than by a very imperfect notice given by Mr. Levy in the first volume of the present series of the Phil. Mag. p. 27. Some detached crystals I have lately obtained have enabled me to give the annexed figure and measurements, as taken from rough planes by the common goniometer.

$$
\begin{aligned}
\mathrm{M}, \mathbf{M}^{\prime} & =127^{\circ} \\
\mathbf{M}, h & =11630^{\prime} \\
\mathbf{M}, e & =16918 \\
h, c & =143
\end{aligned}
$$

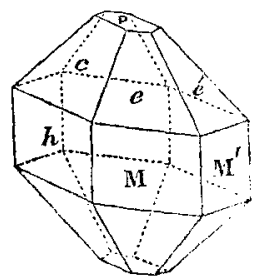

Assuming the symbol of the plane $e$ to be $\stackrel{1}{\mathrm{~B}}, c$ is $\stackrel{1}{\mathrm{E}}$, and $\mathbf{a}$ terminal 
terminal edge of the prism is to a lateral edge nearly as 16 to 19 . Its spec, grav, is $5 \cdot 14$. Hardness, between that of apatite and felspar. The colour of the fragments is brownish yellow, that of gadolinite being green.

\section{Mengite.}

The mineral I am about to describe I have named after Mr. Mengé, who discovered it with the preceding ones near Miask, and whose mineralogical labours have probably not been exceeded by those of any of his contemporaries.

The Mengite occurs in imbedded crystals in masses of felspar and mica in a granitic rock. Its primary form is an oblique rhombic prism, whose terminal and lateral edges are to each other nearly in the ratio of 13 to 18 . The planes are too dull for the reflective goniometer, and those of the larger crystals not sufficiently flat to afford very accurate measurement by the common goniometer.

The crystals of this substance present the accompanying figure, the measurements being nearly as follow :

$$
\begin{aligned}
& \mathrm{P}, \mathrm{M}=100^{\circ} \\
& \mathrm{M}, \mathrm{M}^{\prime}=9530^{\prime} \\
& \mathrm{P}, a=14030 \\
& \mathrm{P}, c=125 \\
& \mathrm{P}, e=13730
\end{aligned}
$$

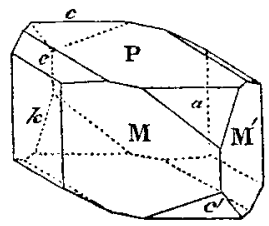

The laws of the planes.............. $\quad a, c, e, k$,

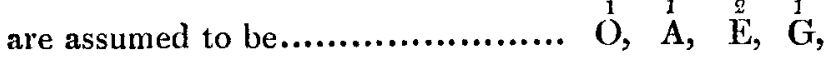

The colour of the crystals is reddish brown. Hardness, between that of apatite and felspar. Spec. grav. 4.88. No regular cleavage. Fracture uneven, and the fractured surface dull. It has not been analysed, but from its specific gravity it is probably metallic. It is frequently attached to and penetrated by crystals of Aeschenite, and sometimes of zircon.

\section{Sarcolite from Vesuvius.}

This mineral appears to have been first observed by Dr. Thomson, who, as Haïy states, sent some fragments of crystals to him for examination, from which he inferred that the cube was its primary form, and conjectured that the mineral might be a variety of analcime. Hence red analcime has been called sarcolite, and the same name has also been given to red gmelinite. A specimen, with which I have been favoured by Mr. Heuland, and a fragnent of a crystal which I have re- 
ceived from Dr. Donati, have enabled me to give the annexed figure and measurements of this substance; the primary form of which is a square prism, whose terminal and lateral edges are in the ratio of 62 to 55 very nearly.

The planes ........... $a 1, a 2, b 1, b 2, c, d, e$, are produced by the laws $\stackrel{3}{\mathrm{~A}}, \stackrel{1}{\mathrm{~A}},{ }_{3} \mathrm{~A}_{3},{ }_{0} \mathrm{~A}_{\frac{1}{3}}, \stackrel{1}{\mathrm{~B}}, \stackrel{1}{\mathrm{G}}, \stackrel{2}{\mathrm{G}}$.

$$
\begin{aligned}
& \mathrm{P}, a 1=157^{\circ} 19^{\prime} \\
& \mathrm{P}, a 2=12833 \\
& \mathrm{P}, d=90 \\
& \mathrm{P}, c=13825 \\
& \mathrm{M}, b 1=15320 \\
& \mathrm{M}, a 2=12334 \\
& \mathrm{M}, b 2=10228 \\
& \mathrm{M}, e=15326 \\
& \mathrm{M}, d=135
\end{aligned}
$$

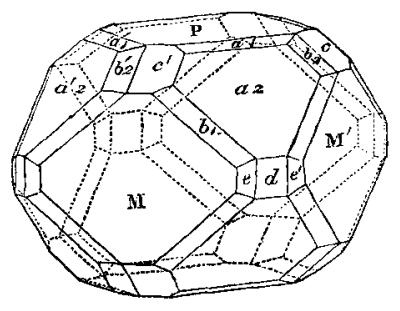

The plane $b 2$, as the symbol denotes, and as appears in the figure, occurs singly on each angle, instead of being accompanied by a corresponding plane on the other side of $c$.

\section{Wollastonite from Vesuvius.}

This is the same mineral as was, according to the ticket accompanying specimens from Vesuvius, formerly named Zurlonite or zurlite. The crystals are generally very imperfect, and the surfaces very dull; a specimen, however, in the possession of Dr. Somerville presented some bright and welldefined crystals, an examination of some of which has enabled me to give the annexed figure and measurements. The primary form is an oblique rhombic prism. There is one cleavage parallel to $\mathrm{P}$, and three others parallel to the three planes $a 3, h, c 2$; that parallel to $h$ is the brightest, and I have supposed it parallel to the edge of the prism, and have thus assumed a different cleavage angle from that usually assigned to tabular spar. I have, however, found a cleavage corresponding to the plane $h$, in specimens from the Bannat, in which the cleavages usually observed and hitherto quoted are those parallel to $\mathrm{P}$ and $c 2$. The ratio of the terminal and lateral edges of the prism which $I$ have taken as the primary is very nearly as 25 to 4.0 , and the obtuse angle of the terminal plane is $91^{\circ} \cdot 56^{\prime}$. The planes are more than usually perfect, several of the measured angles having agreed exactly with those given by calculation. 
Planes $a 1, a 2, a 3, c 1, c 2, e 1, e 2, e 3, f 1, f 2, g, h$.

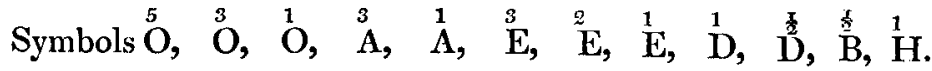

$$
\begin{aligned}
& \mathrm{P}, \alpha 1=159^{\circ} 30^{\prime} \\
& \mathrm{P}, a 2=15023 \\
& \mathrm{P}, a 3=12942 \\
& \mathrm{P}, h=11012 \\
& \mathrm{P}, f 1=13255 \\
& \mathrm{P}, f 2=12042 \\
& \mathrm{P}, \mathrm{M}=10448 \\
& \mathrm{P}, g^{\prime}=868 \\
& \mathrm{P}, e \mathrm{l}=1457 \\
& \mathrm{P}, e 2=13343 \\
& \mathrm{P}, e 3=11533 \\
& \mathbf{P}, g=9352 \\
& \mathrm{M}, \mathrm{M}^{\prime}=9538
\end{aligned}
$$

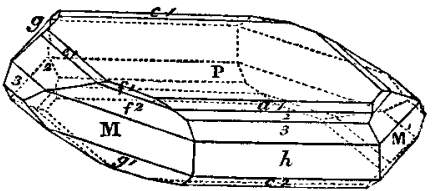

Some of the crystals are hemitrope, the plane of revolution being parallel to the terminal plane.

XXV. On a new Register-Pyrometer, for Measuring the Expansions of Solids, and determining the higher Degrees of Temperature upon the common Thermometric Scale. By J. Frederic Danieli, Esq. F.R.S.**

\section{[With a Plate.]}

$\mathrm{N}$ the year $1821 \mathrm{I}$ published in the Journal of the Royal Institution + an account of a new pyrometer, and the results of some experiments with it, which were the means of correcting the highly erroneous notions which had, up to that time, been generally entertained of the degrees of temperature beyond the boiling point of mercury. The instrument was capable of affording correct determinations, connected in an unexceptionable manner with the scale of the mercurial thermometer; but, although applicable to scientific investigation in careful hands, it could be inserted only into experimental furnaces of a particular construction, which greatly limited its use. The great desideratum still remained of a pyrometer, which might universally be applied to the higher degrees of heat, as the thermometer has long been to the lower; and which, in addition to its use in delicate researches, might effect for the potter, the smelter, the enameler and others, in the

* From the Philosophical Transactions for 1830: Part II., and revised by the Author. + Vol, xi. p. 309 . 